\title{
Comparative Histological Study of the Stomach in Two Species of Iraqi Vertebrates (Magpie Pica pica L. and Small Asian Mongoose Herpestes javanicus E.)
}

\author{
Gazwa D. AL-Nakeeb ${ }^{1}$
}

\author{
Shaimaa A. Abid $^{*}$ \\ Ruwaida A. Abdul Hussein ${ }^{1}$
}

Lamyaa A. Fadhil

Received 1/10/2018, Accepted 30/1/2019, Published 2/6/2019

This work is licensed under a Creative Commons Attribution 4.0 International License.

\begin{abstract}
:
A histological study showed the wall of the stomach in Pica pica and Herpestes javanicus consists of four layers: mucosa, submucosa, muscularis externa and serosa. Also, the present study showed many differences in the histological structures of the stomach for each in both types. The stomach of $P$. pica consists of two portions: the proventiculus and gizzard, while the stomach of $H$. javanicus consists of three portions: cardiac, fundic and pyloric regions. The mucosa layer formed short gastric folds, named plicae. In the proventiculus of P. pica, sulcus is found between each two plicae, but the folds called gastric pits in the gizzard, which are full with koilin. Lamina properia in both types contained gastric glands (straight simple tubular glands) named superficial glands, as well as another gastric gland found in the submucosa layer of the proventiculus in P. pica only named deep gastric glands. The gastric gland in the stomach of $H$. javanicus contained: mucous neck cells and parietal cells positive to AB/PAS stains in cardiac portion, as well as chief cells in fundic portion, but pyloric portion had just mucous neck cells. Muscularis externa in both types formed two muscle layers: inner and outer layer.
\end{abstract}

Key words: Herpestes javanicus, Histology, Pica pica, Stomach.

\section{Introduction:}

The stomach is a large part of the gastrointestinal tract, particularly in mammals and birds, and is responsible for storing and transporting food to the duodenum (1). Histologically, the stomach is composed of four layers: the mucosa, submucosa, muscularis, and serosa (2). The mucosa consists of simple columnar epithelium, and a number of gastric glands, which meet with stomach lumen through gastric pits. The layer of submucosa composed of connective tissue, blood and lymph vessels, while the muscularis layer consists of smooth muscles, and the layer of serosa, which appear as thin layer, covers the stomach from the outside (2). The parts of the stomach in birds differ from those of mammals. The bird's stomach is characterized by two parts: the glandular part called proventiculus and muscular part known of gizzard (3). In some birds, especially predatory birds, the proventiculus expands and secretes gastric juice during food passage and the gizzard, in some birds serves as teeth, stores the food, digestion and pushing the extract food into the intestines (4).

\footnotetext{
${ }^{1}$ Department of Biology, College of Science for Women, University of Baghdad, Baghdad, Iraq.

${ }^{2}$ Department of Biology, College of Science, University of Baghdad, Baghdad, Iraq.

"Corresponding author: shaimaa.awad.abid@gmail.com
}

While the mammalian stomach is divided into three regions; the cardiac region is very narrow, containing cardiac glands, which consists of cells that secret mucus. The second region, the fundus is the largest area of the stomach, consisting of fundic glands characterized by the existence of mucous cells, which are, parietal cells, secrete hydrochloric acid and chief cells which secrete pepsinogen. Lastly, the pyloric region is a narrow region composed of pyloric glands consisting of mucous cells $(2,4)$.

The study was conducted on the stomach to identify the extent of tissue differences and tissue biochemistry in two different types of Iraqi wild vertebrates in the class and the nature of feeding. The magpie, Pica pica (Linnaeus,1758), belongs to Class : Aves. It is an omnivore which feeds on seeds, fruit, small mammals, birds and sometimes on animal remnants, and it also attacks the nests of other birds and prey on their eggs (5). The Small Asian Mongoose Herpestes javanicus (E. Geoffroy Saint - Hilaire, 1818) belongs to Class :Mammalia, and is a carnivore (6).

\section{Materials and Methods:}

Three animals of each species were collected from Baghdad, Al - Ghazel market, 
classified by natural history research center and museum / Baghdad University. Both animals were anesthetized by chloroform inhalation and dissected. The stomach was removed and two part were cut from proventiculus and gizzard in the magpie, but the stomach removed three part were cut from cardiac, fundic and pyloric region in the small asian mongoose.

The parts were fixed in Bouin's fluid solution for 22 hours, and the preparation of the tissue section was then completed. They were stained with Harris's Haematoxylin, and Alcoholic Eosin (7). A special stain was used as Alcian blue (AB) -Periodic Acid- Schiff (PAS) to identify the connective tissue (7), and the slides checked and photographed by using a compound light microscope (Meiji) with a camera.

\section{Results:}

The histological sections showed that the magpie stomach consisted of two parts: a glandular stomach known as Proventiculus and muscular stomach named a gizzard. The mucosa layer appears in the Proventiculus, which are finger like shaped folds named a plicae, which are confined by the sulcus. The surface is lined by non- ciliated simple columnar epithelium, with a basal oval nucleus. The height of cells vary in length, appearing shorter in the base part of the fold than in the top, all of them based on the basement membrane and the lamina properia is composed of loose connective tissue which is rich in blood vessels as well as the presence of gastric glands (simple tubular gland called superficial gastric gland), which showed a positive response to $\mathrm{AB} / \mathrm{PAS}$ stain, which opens in the lumen of stomach (Fig.1A,B,C). The submucosa considered as a connective tissue, occupies most of the wall of the stomach. Due to occurrence of a huge gland in this layer called deep gastric glands (compound tubular alveolar glands that separate from connective tissue) as well as blood vessels (Fig.2A), each gland consists of a number of differentiated alveolar adenomers which vary in size. Each adenomer is composed of secretory units, with each unit consisting of simple cuboidal epithelium (Fig.2B). The histological sections showed that the center of the gland is composed of the tertiary ducts, which collect the excretory material from the secretory units. The stomach cavity has channels, which flow into the main duct. The unit consists of cuboidal cells arranged hierarchically with a center that represents the cavity in which glandular secretions are collected (Fig.2A). The muscularis externa consists of three smooth muscle fiber layers: the inner layer appears very thin with muscle fibers that extend to support the deep gastric glands, the middle layer that contains muscles arranged longitudinally, and the outer layer that is arranged circularly (Fig.3A). Finally, serosa is composed of loose connective tissue with mesothelium (Fig. 3B). Sections showed that, the mucosa of the gizzard consists of simple columnar epithelium which forms short folds, with gastric pits found between each two folds (Fig.4A). The lamina properia is composed of areolar loose connective tissue and punctuated by simple tubular glands, which are separated from each other by loose connective tissue. The gastric glands open at the base of the gastric pits among the folds, and then the gastric pit fills with an excretory secretion of gastric glands (vertical koilin) covering the gastric folds with horizontal koilin. This represents one of the secretions of the gastric gland and the results showed that the koilin showed a positive response for $\mathrm{AB} / \mathrm{PAS}$ stain (Fig.4B). Muscularis mucosa appeared scattered and is located in the base of the glands (Fig.5A). The second layer of gizzard, submucosa is composed of loose connective tissue containing blood vessels (Fig.5A). The muscularis externa appeared as a very thick layer, composed from bundles of smooth muscle fibers arranged circularly. These bundles were separated by loose connective tissue. The sections showed where the bundles intersect (Fig.5B). The muscularis externa is covered from the outside by serosa with mesothelium, which appeared to be very rich in the blood vessels (Fig.5C). 


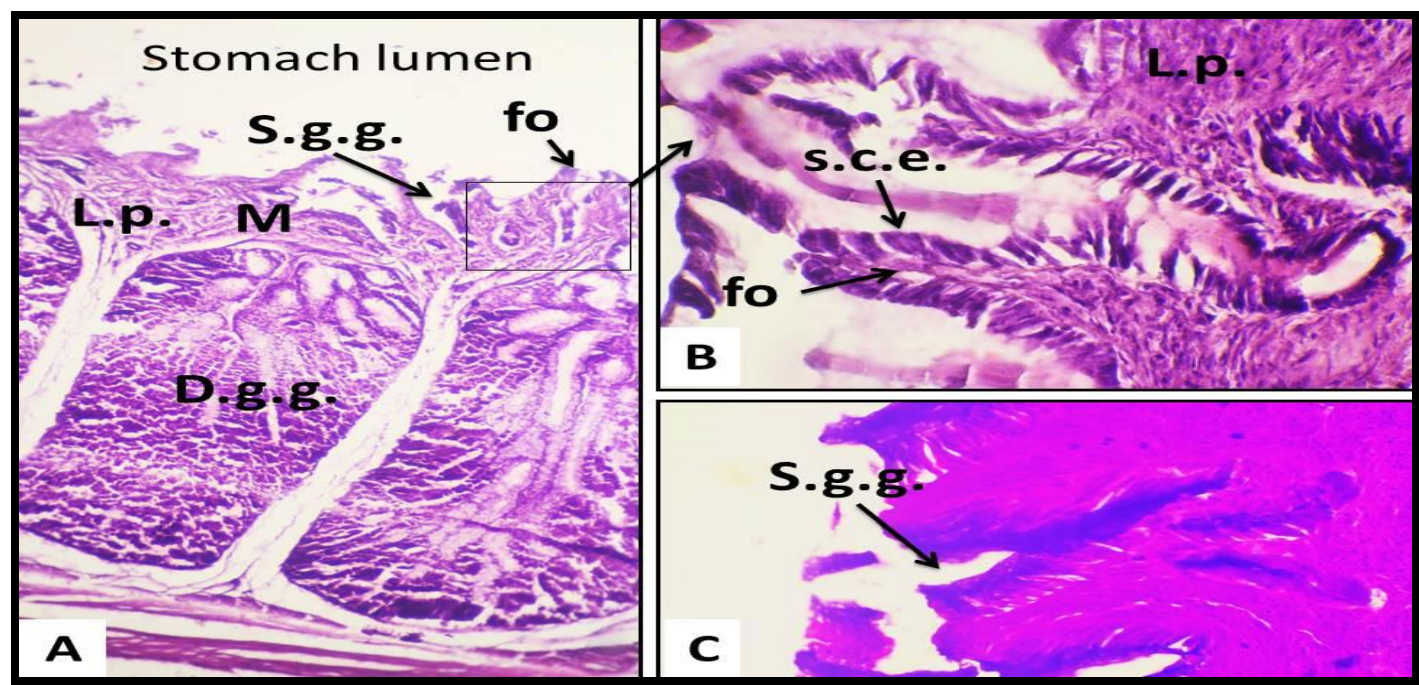

Figure 1. Transverse section showing the folds and gastric gland of the Proventiculus (A:100x,B: 400x (H\&E Stain) \& C:400x (AB/PAS Stain)). (fo) fold,(S.g.g.) Superficial gastric gland, (M) Mucosa, (L.p.) Lamina properia, (D.g.g.) Deep gastric gland, (s.c.e) simple columnar epithelium

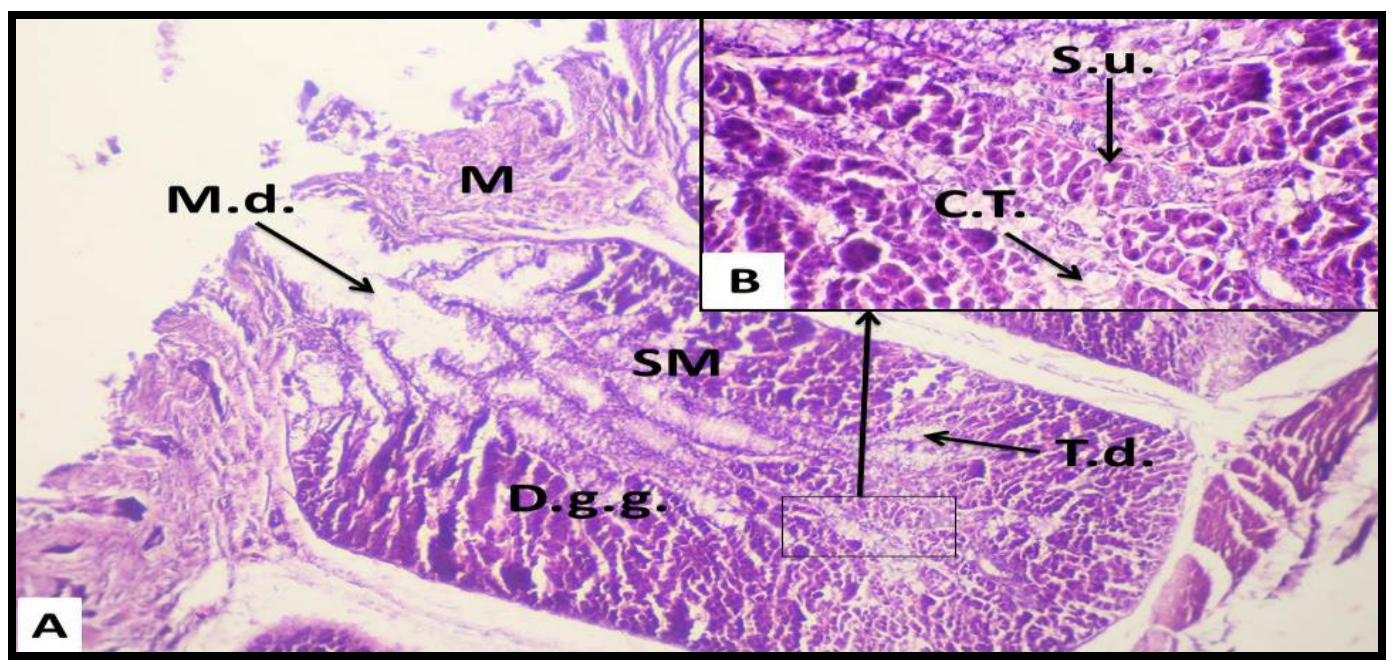

Figure 2. Transverse section showing the submucosa of the Proventiculus (H\&E Stain) (A:100x \&B: 400x). (M) Mucosa, (SM) Submucosa, (D.g.g.) Deep gastric gland, (M.d.) Main duct, (T.d.) Tertiary duct, (S.u.) Secretory unit, (C.T.) Connective Tissue

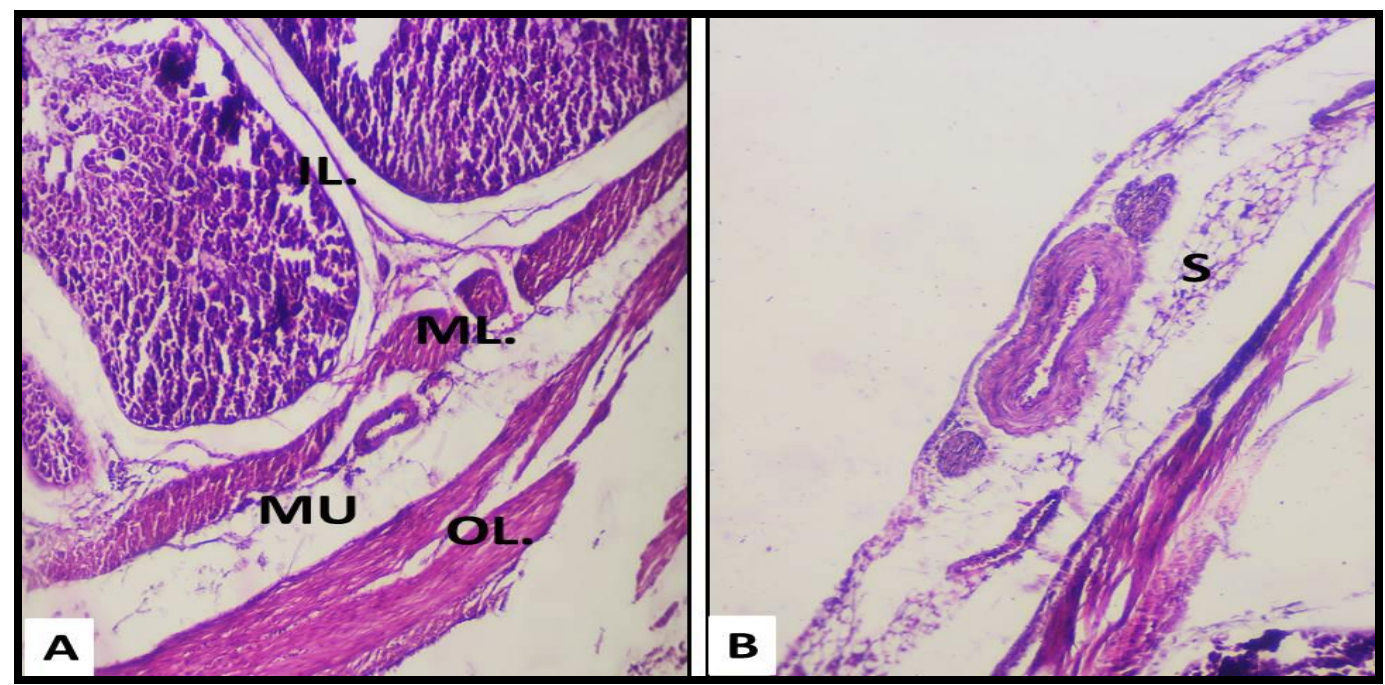

Figure 3. Transverse section showing the muscularis externa and the serosa of the Proventiculus (H\&E Stain) (A\&B:100x). (MU) Muscularis externa, (IL.) Inner Layer, (ML.) Middle Layer, (OL.) Outer Layer, (S) Serosa 


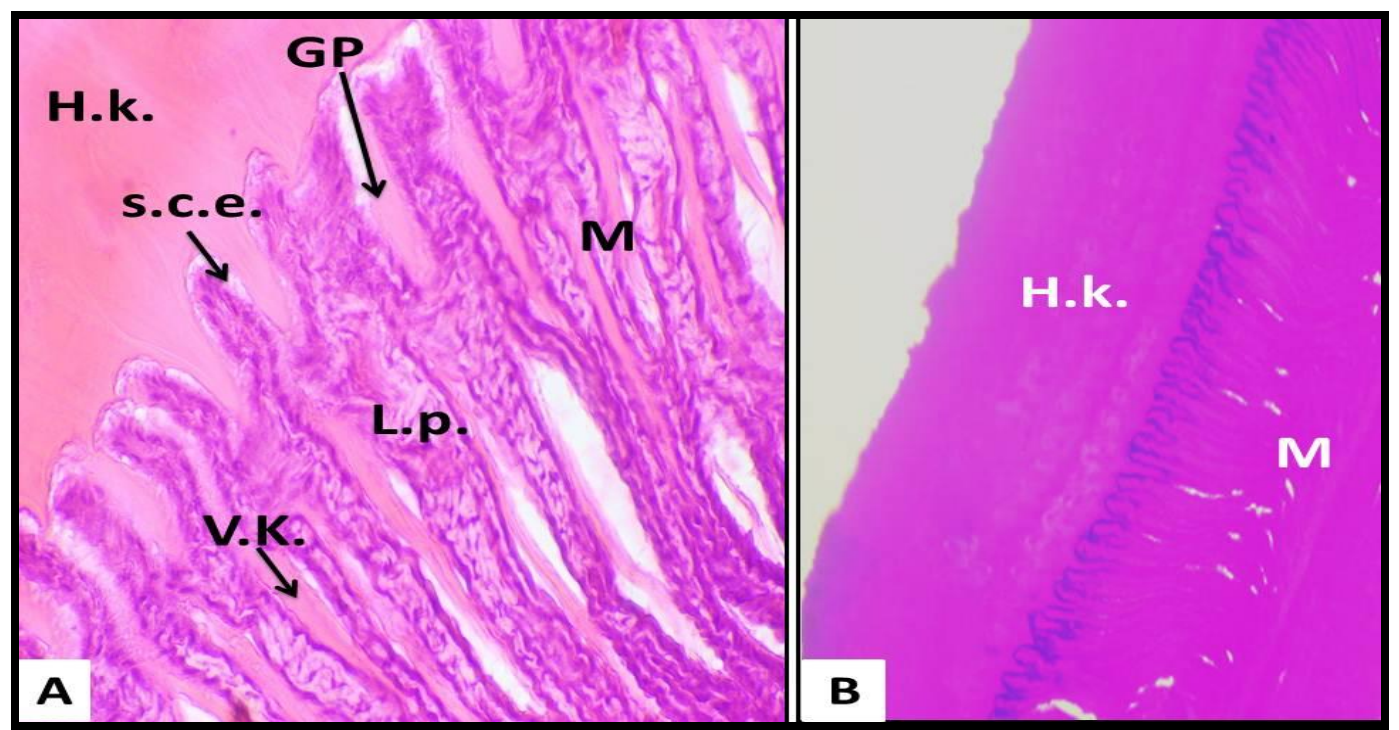

Figure 4. Transverse section showing the mucosa of the gizzard (A\&C:400x (H\&E Stain) and B: 100x (AB/PAS Stain)). (M) Mucosa, (L.p.) Lamina properia, (GP) Gastric Pit, (s.c.e.) simple columnar epithelium, (H.K.) Horizontal Koilin, (V.K.) Vertical Koilin

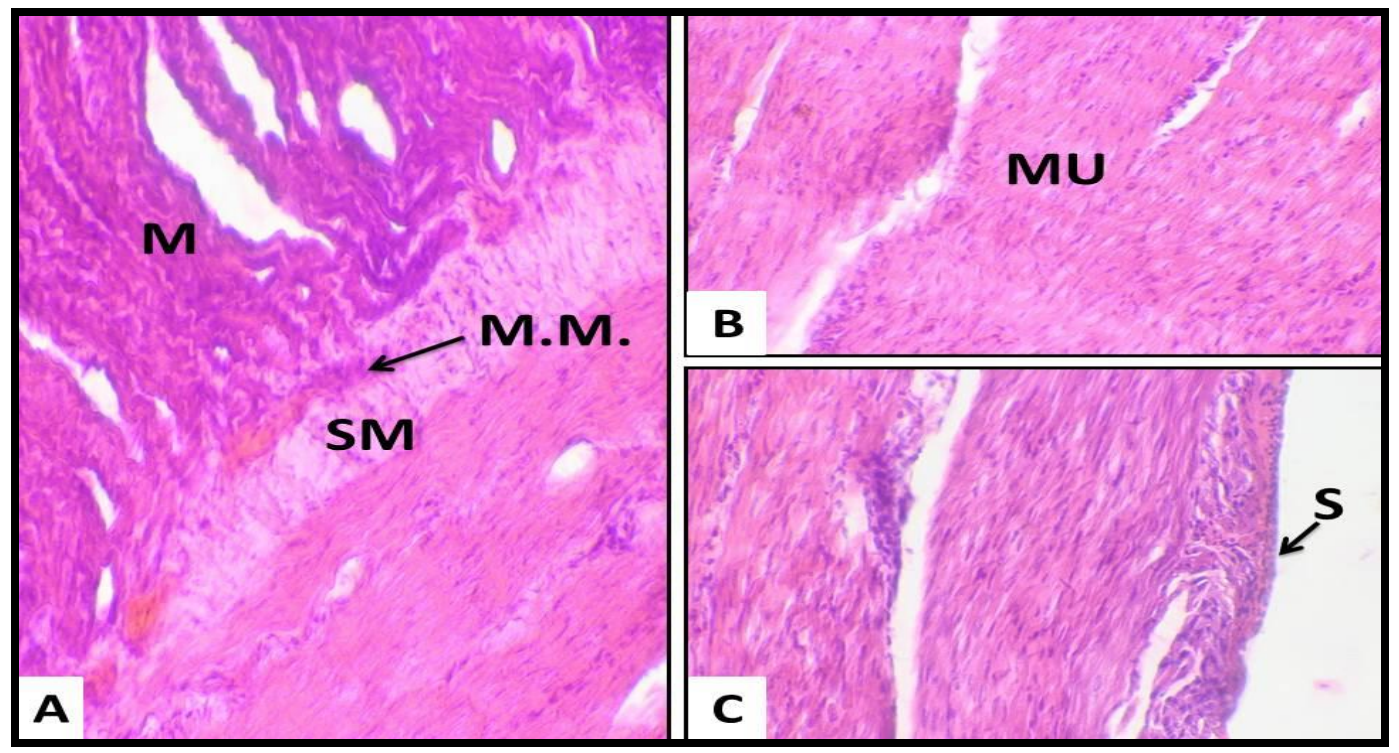

Figure 5. Transverse section showing the submucosa, muscularis externa and serosa of the gizzard (H\&E Stain) (A,B\&C:400x). (M) Mucosa, (M.M.) Muscularis Mucosa, (SM) Submucosa, (MU) Muacularis externa, (S) Serosa

The histological study of the stomach for the small asian mongoose consisted of cardiac, fundic, and pyloric regions. The lining of the cardiac stomach contains characteristic primary and secondary gastric folds (Fig.6). The mucosa layer consists of three layers: starting from the frontal area of the stomach lumen is called epithelium lining, which consists of non -ciliated simple columnar epithelium, formed by gastric pits (Fig. 7A), epithelium which includes two types of epithelial cells: the dominant type is mucous neck cells which are positive for the AB/PAS stain(Fig. $7 \mathrm{~B}, \mathrm{C})$. The second type is parietal cells of spherical shape carrying red color with central nucleus, and appeared scattered within the epithelium (Fig.7D). The epithelium is based on loose connective tissue is called lamina properia. The second layer of the mucosa is interspersed with gastric glands. The two types are: a simple tubular gland, and a type that occupies most of the cardiac stomach, which appears in branched simple tubular gland (Fig.8A,B). The third layer of mucosa is muscularis mucosa, which is an internal muscle layer arranged in a circular form and outer layer arranged in a longitudinal form that appears to be thicker than the secondary folds (Fig.8C), followed by a submucosa which is a loose connective tissue interspersed with many blood vessels and collagenous fiber which is missing gastric glands. The third layer of the stomach wall is the muscularis externa, which is muscle fibers containing two layers: an inner layer with circular arrangement and outer layer with a 
longitudinal arrangement that appears thick within the wall of the stomach. Finally, the wall of the stomach is surrounded by serosa which is composed of simple squamous epithelium (mesothelium) (Fig.9A,B,C). Histological sections showed the gastric folds of the fundic stomach were more regular, with the fundic glands (branched simple tubular glands) in type (Fig.10). The epithelium consisted of three types of cells, mucous neck cells, which appeared as short columnar cells with longitudinal nuclei located in the upper region of the gastric pits and these cells are positive for AB/PAS stain, parietal cells dominant and occupy most of the tissue, with an oval spherical in shape and a pale nucleus found in the core of the cell. Chief cells were found in between the parietal cells, which are smaller than parietal cells with a dark central nucleus (Fig.11A,B,C,D). The inner layer of the muscularis externa is composed of smooth muscle fibers arranged circularly, but appeared thicker than the outer layer, which was composed of a longitudinal arrangement of smooth muscle fibers. Serosa is thin layer rich with blood vessels (Fig. $12 \mathrm{~A}, \mathrm{~B}, \mathrm{C})$. The pyloric stomach had pyloric glands represented as simple tubular glands in type, mucosa formed from mucous neck cells, which appeared to be positive for AB/PAS stain (Fig.13A,B,C) and lack parietal cells. The inner layer of muscularis externa is thinner than the outer layer, and the serosa consisted of one row of simple squamous epithelium (mesothelium) (Fig. $14 \mathrm{~A}, \mathrm{~B}, \mathrm{C})$.

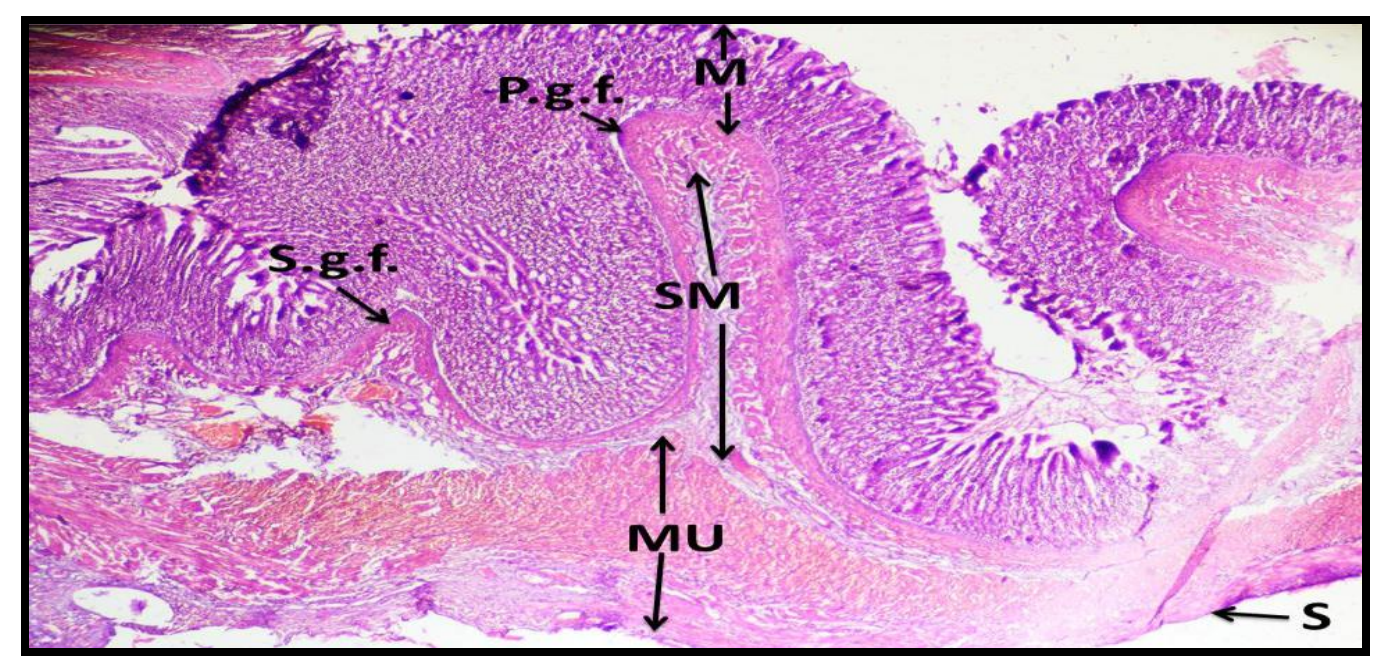

Figure 6. Transverse section showing the folds and layers of the cardiac stomach (H\&E Stain) (100x). (p.g.f.) primary gastric fold, (s.g.f.) secondary gastric fold, (M) Mucosa, (SM) Submucosa, (MU) Muscularis, (S) Serosa

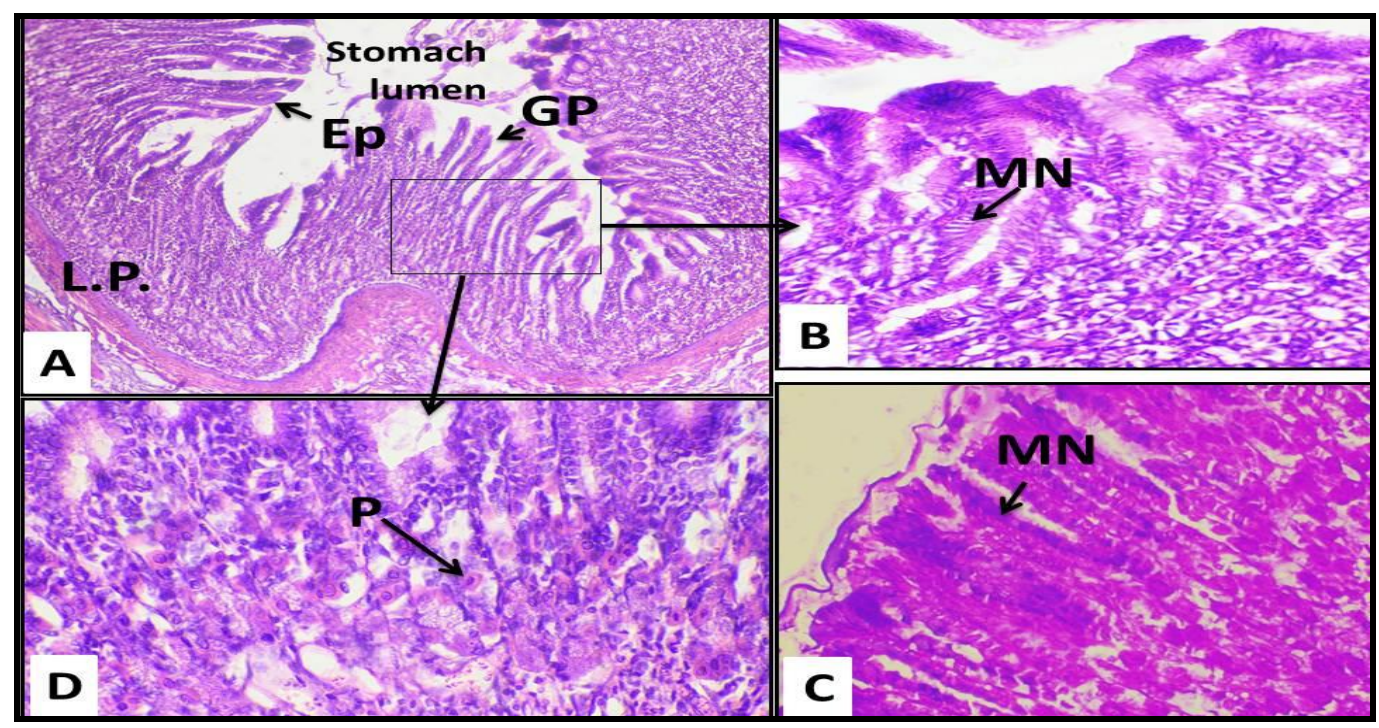

Figure 7. Transverse section showing the mucosa layers (A:100x, B\&D:400x (H\&E stain) \& C:400x (AB/PAS stain)). (Ep) Epithelium, (GP) Gastric Pit, (L.P.) Lamina properia, (MN) Mucous Neck cell, (P) Parietal cell 


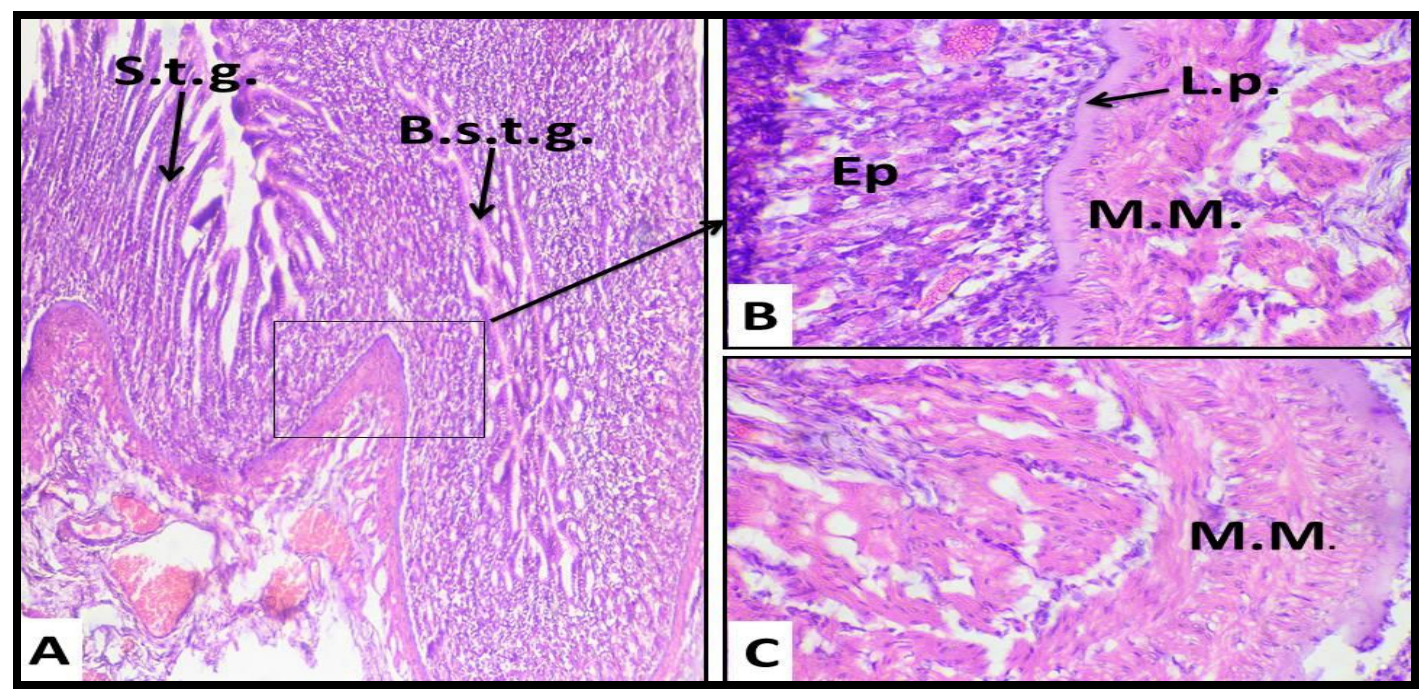

Figure 8. Transverse section showing the lamina properia, gastric glands, and muscularis mucosa (H\&E stain) (A: 100x, B\&C:400x). (S.t.g.) Simple tubular gland, (B.s.t.g.) Branched simple tubular gland, (Ep) Epithelium, (L.p.) Lamina properia, (M.M.) Muscularis Mucosa

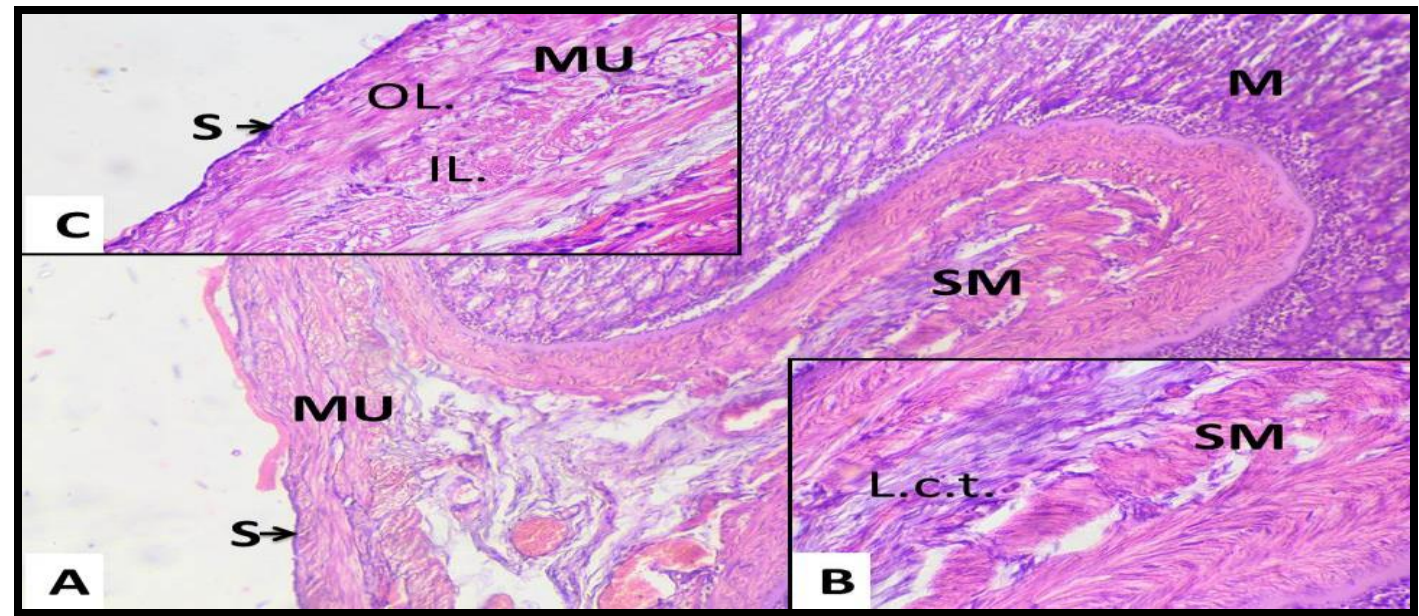

Figure 9. Transverse section showing the histological structure of the cardiac stomach (H\&E stain) (A: 100x, B\&C:400x). (M) Mucosa, (SM) Submucosa, (MU) Muscularis, (S) Serosa, (L.c.t.) Loose connective tissue, (IL.) Inner Layer, (OL.) Outer Layer

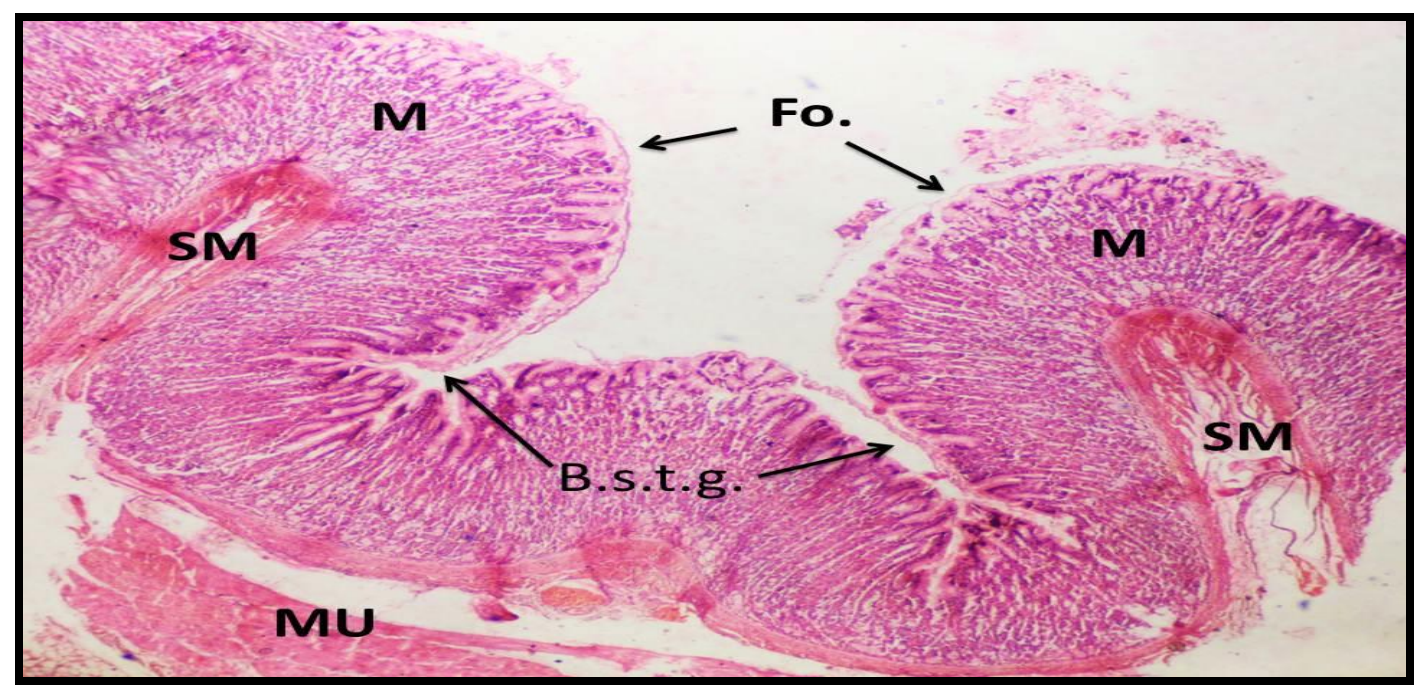

Figure 10. Transverse section showing gastric fold and fundic glands in fundic stomach (H\&E stain) (100x). (Fo.) Fold, (M) Mucosa, (SM) Submucosa, (MU) Muscularis, (B.s.t.g.) Branched simple tubular gland 

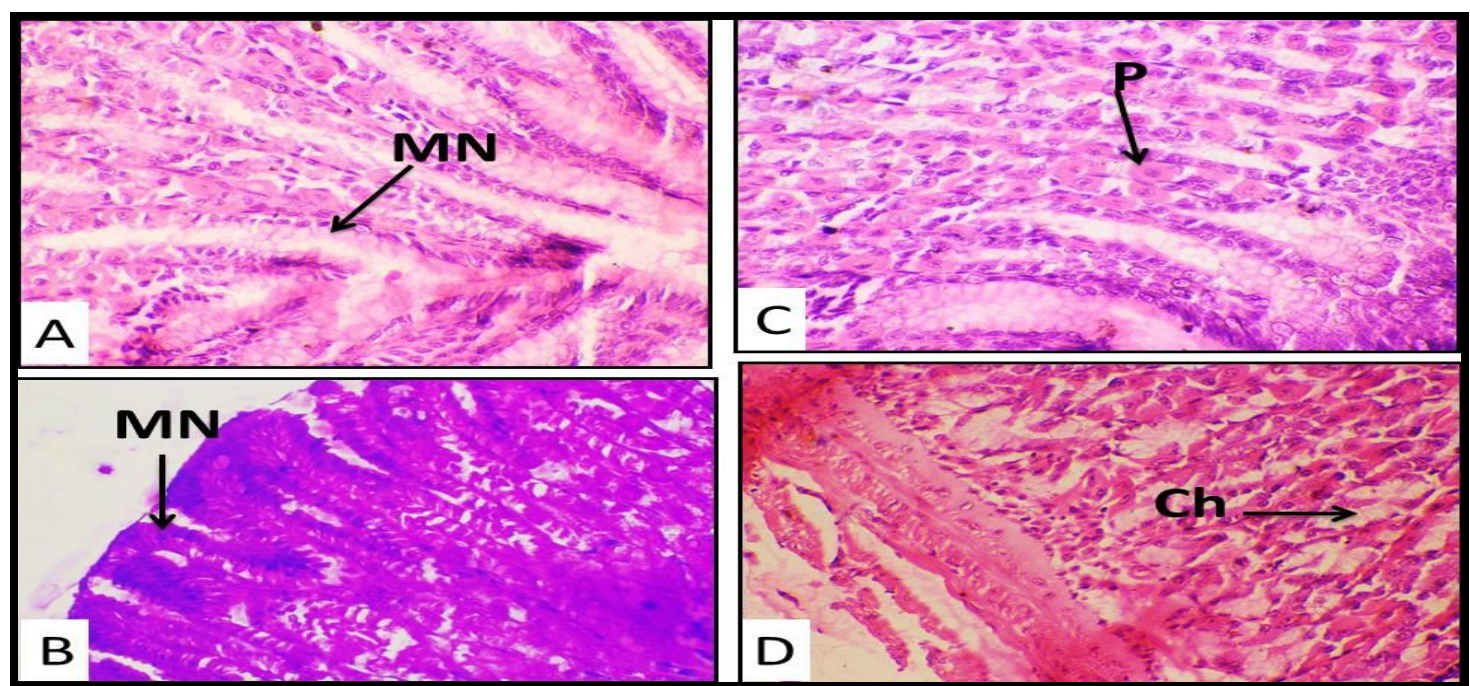

Figure 11. Transverse section showing epithelial tissue cells of the fundic stomach $(\mathrm{A}: 400 \mathrm{x}(\mathrm{H} \& \mathrm{E}$ stain),B:400x (AB/PAS stain),C\&D:400x (H\&E stain)). (MN) Mucous Neck cell, (P) Parietal cell, (Ch) Chief cell

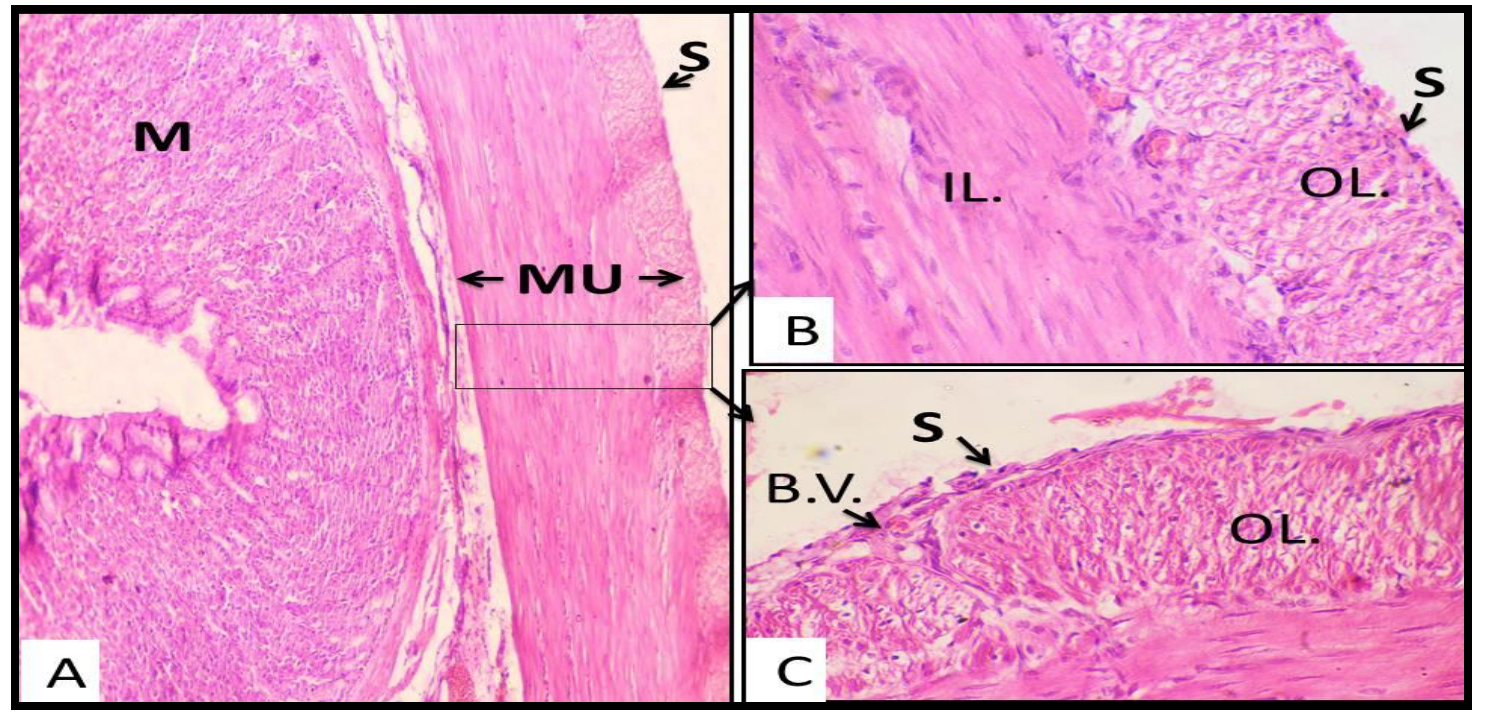

Figure 12. Transverse section showing muscularis externa and serosa (H\&E stain) (A: 100x, B\&C:400x). (M) Mucosa, (MU) Muscularis, (S) Serosa, (IL.) Inner Layer, (OL.) Outer Layer, (B.V.) Blood Vessel

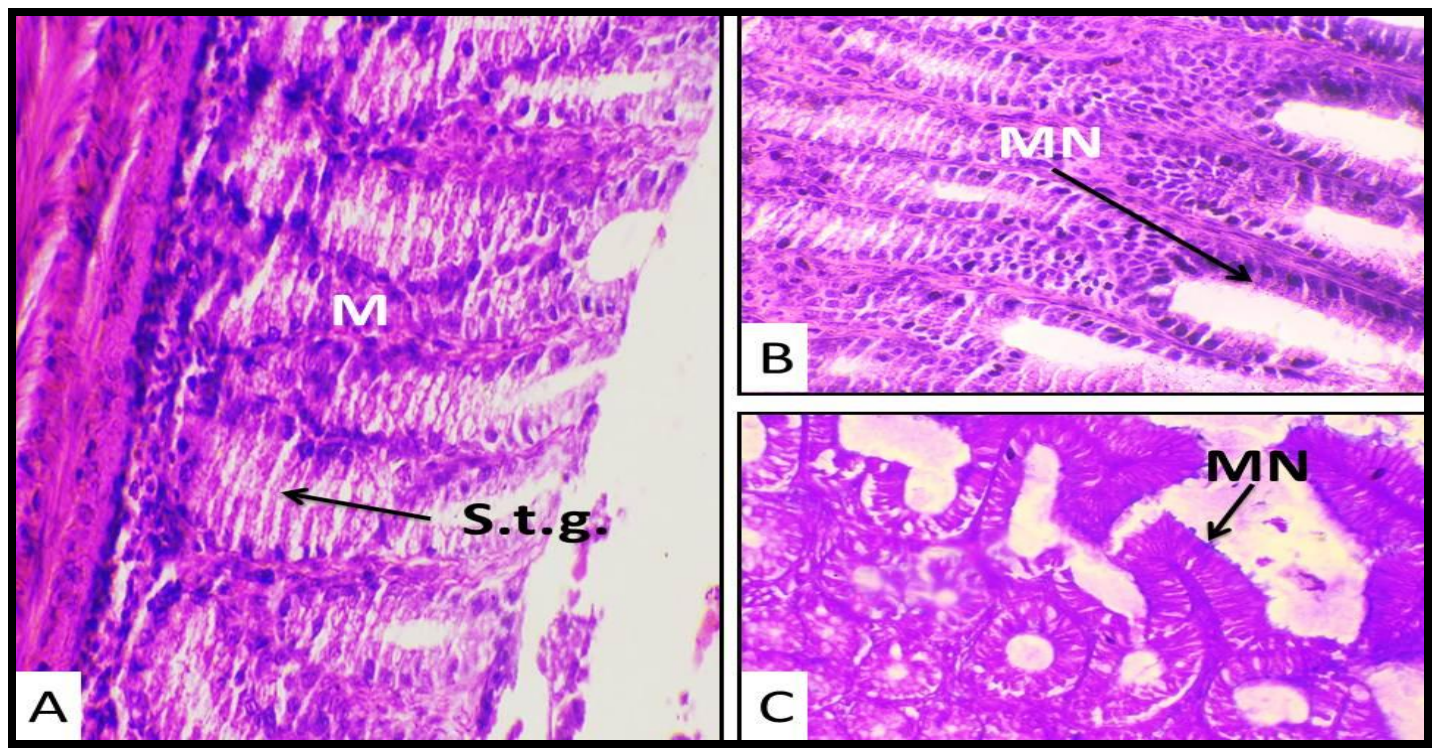

Figure 13. Transverse section showing pyloric region (A,B:400x (H\&E stain) \&C:400x(AB/PAS stain)). (M) Mucosa, (S.t.g.) Simple tubular gland, (MN) Mucous Neck cell 


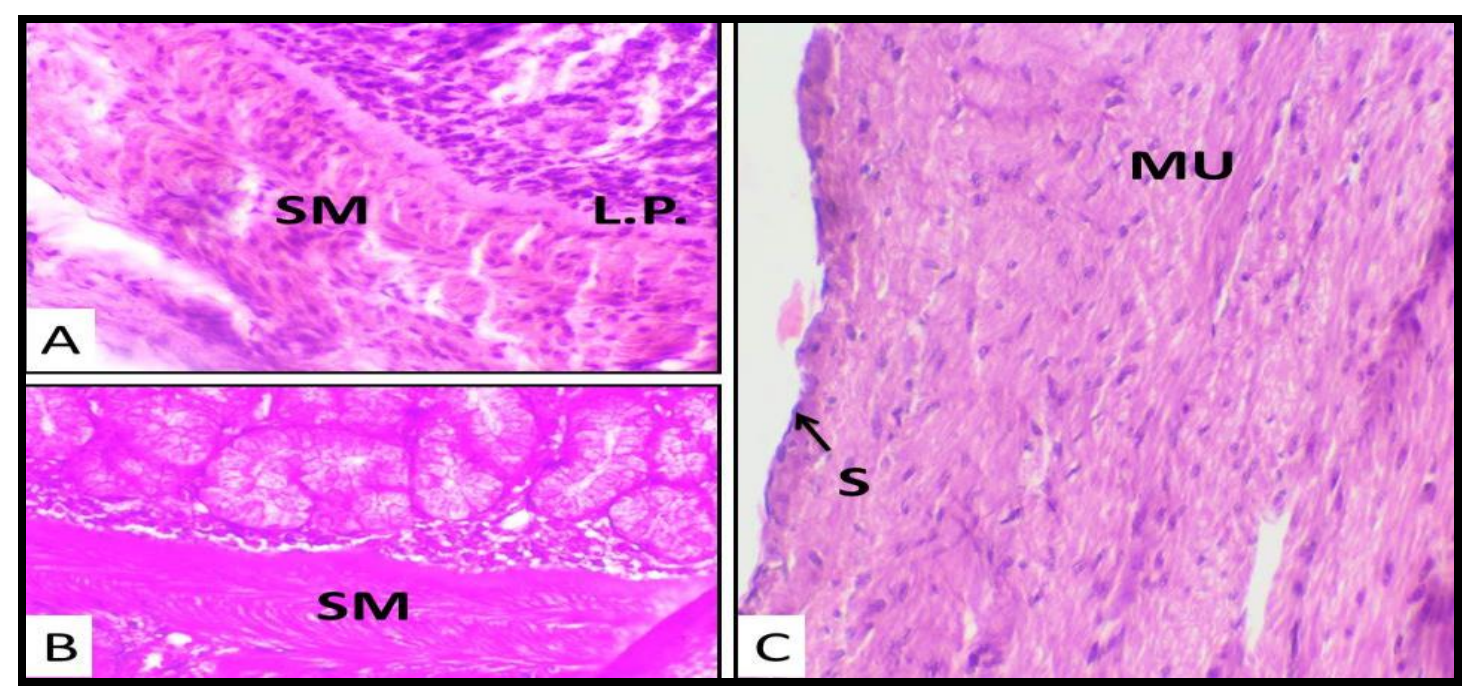

Figure 14. Transverse section showing pyloric region (A:400x(H\&E stain), B:400x(AB/PAS stain) \&C:400x(H\&E stain)). (SM) Submucosa, (MU) Muscularis, (S) Serosa, (L.p.) Lamina properia

\section{Discussion:}

Many references refer to the nature of the food eaten by animal, and the way itis obtained will determine the histological structure of the digestive tract (4). The results showed that the stomach of the magpie was composed of two parts: proventiculus and gizzard, similar to many birds $(8,9)$, while the stomach of the small asian mongoose consist of three regions: cardiac stomach, fundic stomach and pyloric stomach, which is consistent with (10). The stomach wall in both species consist of four main layers: mucosa, submucosa, muscularis externa and serosa. This is characteristic of the stomach wall in all vertebrates $(11,12)$. However, there are clear differences in the histological structure of the stomach in the magpie and the small asian mongoose according to the type of nutrition. The proventiculus in magpie composed of mucosa which consist of folds, which is consistent with $(13,14)$, due to the nature of magpie feeding (omnivorous) so the proventiculus needs chemical digestion. These folds increase the surface area of the stomach mucosa lined with simple columnar epithelium. The lamina properia is composed of loose connective tissue, as well as the presence of superficial gastric glands that open in the lumen of stomach. These results are consistent with (15). These glands showed a positive response to the $\mathrm{AB} / \mathrm{PAS}$ stain due to the presence of mucopolysaccharides, so it was dyed in blue acid reagent, consistent with $(11,16)$. While the submucosa consisted loose connective tissue with deep gastric glands that occupy most of the connective tissue, this is similar to the glands in the black-tailed Crake (Porzana bicolor), which releases mucins and pepsinogen into the stomach cavity through the secretory canal (17). The muscularis externa consisted of three layers: the inner is very thin layer of the muscle fibers extending to support the deep glands, the intermediat layer appeared thicker than the first layer and longitudinally arranged, while the outer layer is circularly arranged. The thickness of the muscularis externa may be help to empty the secretions of the deep gastric glands. These results are consistent with (13) when he study on the Larus canus. The serosa consisted of loose connective tissue. This is consistent with (13). The gizzard (mechanical) wall of Magpie was thicker than itis in the proventiculus (glandular). The mucosa consisted simple columnar epithelium in the form of short folds confined by gastric pits. The lamina properia contained simple tubular glands that open at the base of the gastric pits among folds and fill the cavity with koilin, which is consistent with (18). The koilin appears to be positive for AB/PAS stain, because koilin is protein-like substance $(16,19)$. The muscularis mucosa was scattered but located near the base of the glands, which is similar to the Hasoon (11). Submucosa consisted of a loose connective tissue with blood vessels. The muscularis externa is very thick and consisted of several rows of smooth muscle layers, and these results agreed with (13). This agreement may be because the magpie is a mixed feeding and the muscles are well formed and responsible for shrinking of the gizzard in order to crushing food. The serosa appears to be very rich in the blood vessels supplying the muscularis externa, consistent with (11).

The cardiac stomach is formed in the small asian mongoose of unequal gastric folds, while the gastric folds in fundic stomach were more regular. The presence of folds lead to an increase in the surface area of the stomach to produce mucus and enzymes that help in the process of fermentation 
and digestion of food (20). The mucosa consisted of three layers: the epithelium lining is formed by gastric pits, these result agree with (21). The epithelium is composed of two types of cells: mucous neck cells positive for AB/PAS stain, may be due to these cells produce mucus acidic in type, so stained with blue color, parietal cells positive for AB/PAS stain, may be due to these cells secrete serotonin acidic in type so itis colored with blue. The epithelium in the fundic stomach is composed of three types of cells: mucous neck cells, parietal cells and chief cells, which showed a positive response to the $\mathrm{AB} / \mathrm{PAS}$ stain, these results are similar to (1), whereas parietal cells produce hydrochloric acid and chief cells secrete pepsinogen. The epithelium in pyloric stomach is composed of mucous neck cells and absence of parietal cells and this result consistent with (1). The lamina properia is interspersed with simple tubular glands and branched simple tubular glands in cardiac stomach, while in the fundic stomach there were only branched simple tubular glands, and in the pyloric stomach there were simple tubular glands. These results are not consistent with (10), which may be due to the feeding behaviors of the small asian mongoose (carnivorous), which has a real glandular stomach. The submucosa lacked gastric glands, and this result agreed with (1). The muscularis externa composed of two layers: an inner layer and outer layer, which appeared to be different in thickness within the wall of the stomach, and finally the serosa was consisted of simple squamous epithelium (mesothelium), these results are similar to (1).

\section{Conflicts of Interest: None.}

\section{References:}

1. Treuting PM, Dintzis SM, Montine KS. Comparative Anatomy and Histology A Mouse, Rat and Human Atlas. $2^{\text {nd }}$ ed. Academic press is an imprint Elsevier: Mica Haley; 2018. 194 - 201 pp.

2. Mescher AL. Junqueira's basic histology text and atlas. $13^{\text {th }}$ ed. McGraw Hill; 2013. $301-309$ Pp.

3. Scanes CG. Sturkie's Avian physiology. $6^{\text {th }}$ ed. Academic press is an imprint of Elsevier; 2015. 340 Pp.

4. Gali MA, Dauod HAM. Comparative anatomy of chordates. $2^{\text {nd }}$ ed. Dar Al - Doctor the administrative and economic Sciences. 2014; 482 - 483 Pp.

5. Allose B. Iraqi birds. The third part. Press the Nexus - Baghdad.1962; 47 - 48 Pp.

6. Al-Sheikhly OF, Haba MKh. The field guide to the wild mammals of Iraq. Faraaheedi house publishing and distribution / Baghdad. 2014; 36 Pp.
7. Suvarna SK, Layton C, Bancroft JD. Bancroft's theory and practice of histological techniques, $7^{\text {th }}$ ed. Churchill livingstone Elsevier. 2013; 87 - 176 Pp.

8. Zhu L. Histological study of the oesophagus and stomach in grey-backed shrike (Lanius tephronotus). Int J Morphol. 2015 Feb; 33(2):459 - 64.

9. Batah A L, Selman HA, Saddam M. Histological study for stomach (proventiculus and gizzard) of coot bird Fulica atra. Diyala Agric Sci J. 2012 Jan;4(1) 9 -16 .

10. Shoeib MB, Hassanin A, Elnasharty M. Morphological and morphometric characteristics of gastric mucosa in western grey kangaroo (Macropus fuliginosus). J Adv Vet Anim Res. 2015 Sep; 2(1): 40 -8 .

11. Hasoon KK. Histological and histochemical study of the alimentary canal in laughing dove Streptopelia senegalensis. MSc [Thesis]. Baghdad: University of Baghdad; 2015.

12. Calamar CD, Patruica S, Dumitrescu G, Bura M, Dunea IB, Nicula M . Morpho-histological study of the digestive tract and the annex glands of Chinchilla laniger. Sci Pap Anim Sci Biot. 2014 May;47(1): 269 -74 .

13. Al-hamadany AMTA. Comparative Anatomical, Histological with Developmental Study at Light and Electron Microscopic Level of Eye and Alimentary Canal for three Species of Birds which Differ in Nutrient Nature. PhD [dissertation]. Mosul: University of Mosul; 2012.

14. Ventura A, do Nascimento AA, do Santos MAJ, Vieira - Lopes DA, Salea A, Pinheiro NL. Histological description of morphogenesis of the gastroesophageal mucosa of Gallus gallus domesticus (Linnaeus, 1758). Int J Morphol. 2013 Nov; 31(4): $1331-39$.

15. Al-juboury RWS. Comparative anatomical and histological study on the digestive tract in two Iraqi birds common wood pigeon Columba palumbus (L.) and barn owl Tyto alba (Scopoli). PhD [dissertation]. Babylon:University of Babylon; 2016.

16. Hamdi H, El-Ghareeb AW, Zaher M, AbuAmod F. Anatomical, Histological and Histochemical Adaptations of the Avian Alimentary Canal to Their Food Habits: II- Elanus caeruleus. Int J Sci Eng Res. 2013 Oct; 4(10): $1355-64$.

17. Zhu L. Histological and Histochemical Study on the Stomach (Proventriculus and Gizzard) of Black-tailed Crake (Porzana bicolor). Pak J Zool . 2015 Jun;47(3): $607-16$.

18. Al-Saffar FJ, Al-Samawy ERM. Histomorphological and Histochemical Studies of the Stomach of the Mallard (Anas platyrhynchos). Asian J Anim Sci. 2015 Sep; 9(6): $280-92$.

19. El Nahla SMM, El Mahdy TOM, Basha WAA. Morphofunctional adaptation of the stomach of the cattle egret (Bubulcus ibis) to the types of its food. Sues Can Vet Med J. 2011Jun;16(2): 93 - 111.

20. Scopin AE, Gashkova IV, Saveljev AP, Abramov AV. Histologic features of the gastrointestinal tract of Laonastes aenigmamus (Rodentia: Diatomyidae). Vertebr Zool . 2015 May;65(1): 151 - 63. 
21. Strobel S, Encarnacao JA, Becker NI, Trenczek TE. Histological and histochemical analysis of the gastrointestinal tract of the common pipistrelle bat
(Pipistrellus pipistrellus). Eur J Histochem. 2015 Apr; 59(2): 107 - 15.

\title{
دراسة نسجية مقارنة للمعدة في نوعين من الفقريات العراقية ( العقعق .Pica pica L و ابن عرس الاسيوي

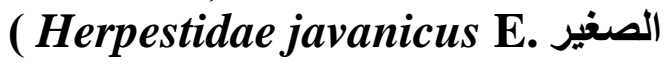

\author{
غزوه درويش النقيب1

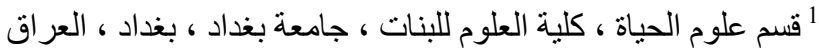

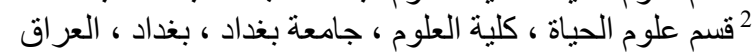

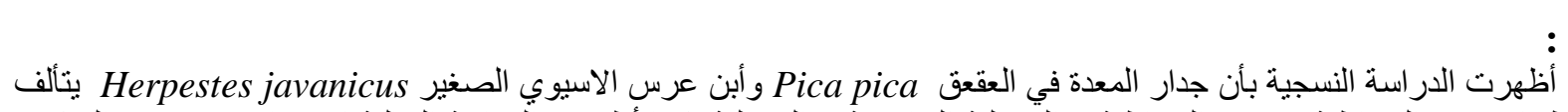

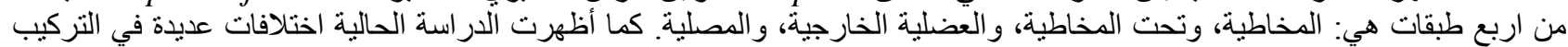

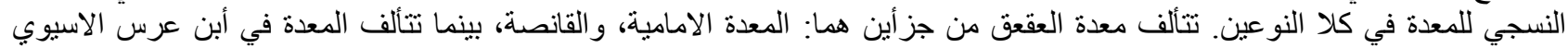

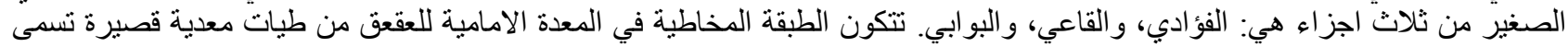

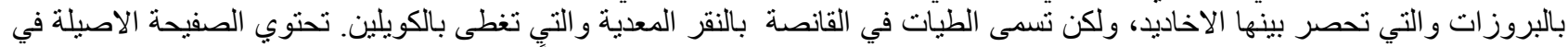

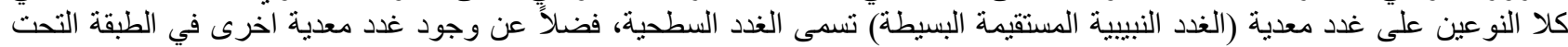

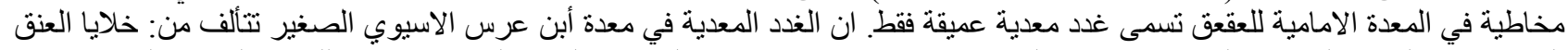

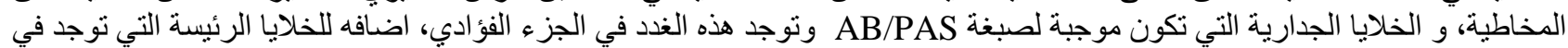

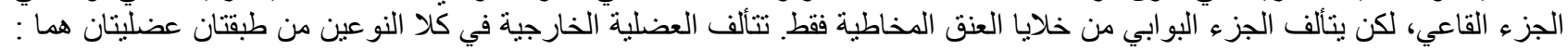

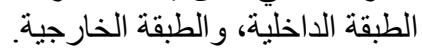

الكلمات المفتاحية: أبن عرس الاسيوي الصغير، نسجي، العقعق، المعدة. 